\title{
Representaçôes sociais de mulheres portadoras de hipertensão arterial sobre sua enfermidade: desatando os nós da lacuna da adesão ao tratamento na agenda da Saúde da Família
}

\author{
I 1 Amanda Gomes Ribeiro, ${ }^{2}$ Rosângela Minardi Mitre Cotta, ${ }^{3}$ Sônia Machado \\ Rocha Ribeiro, ${ }^{4}$ Cristina Maria Ganns Chaves Dias, ${ }^{5}$ Raquel Maria Amaral Araújo I
}

Resumo: A falta de adesão ao tratamento e a consequente falta de controle da hipertensão arterial (HA) representam um grande desafio à Atenção Primária no Brasil. Compreender a relação subjetiva dos portadores de HA com a enfermidade pode ampliar as possibilidades de medidas de controle da HA mais efetivas. O objetivo deste trabalho foi conhecer e analisar as representaçōes sociais de mulheres portadoras de HA sobre a doença e seu convívio familiar. Fizeram parte do estudo 26 mulheres diagnosticadas com HA e cadastradas em uma Unidade de Atenção Primária à Saúde do município de Porto Firme, MG. O estudo fundamentou-se na pesquisa qualitativa e elegeu as representaçôes sociais como princípio teórico-metodológico. Os dados, obtidos por meio de grupos focais, entrevistas individuais e anotaçôes em diário de campo, foram examinados através da análise de conteúdo. Nas análises emergiram os atrativos semânticos que retratavam as representaçôes das mulheres sobre HA - efeitos psicológicos/sentimentos ligados ao diagnóstico da HA; o cotidiano do portador de HA e as mudanças em seu dia a dia; e o convivio familiar com HApor meio das quais se identificaram diferentes dimensões e espaços ligados à adesão, no âmbito individual e coletivo, destacando-se o acesso à informação associado ao suporte social como fator favorável à adesão ao tratamento.

> Palavras-chave: pesquisa qualitativa, educação em saúde, hipertensão.

\author{
${ }^{1}$ Mestre em Ciência da \\ Nutrição, UFV. Endereço \\ eletrônico: amandagribeiro@ \\ hotmail.com \\ 2 Profa. adjunta do Depto. de \\ Nutrição e Saúde, Universidade \\ Federal de Viçosa (UFV): \\ Doutora em Saúde Pública \\ pela Universidade de Valência, \\ Espanha. Endereço eletrônico: \\ rmmitre@ufv.br \\ ${ }^{3}$ Profa. adjunta do Depto. de \\ Nutrição e Saúde, UFV; Doutora \\ em Bioquímica Agrícola pela \\ UFV. Endereço eletrônico: \\ sribeiro@ufv.br \\ ${ }^{4}$ Profa. associada do Depto. \\ de Enfermagem e Medicina, \\ UFV; Doutora em Patologia pela \\ Universidade Federal de Minas \\ Gerais. Endereço eletrônico: \\ cdias@ufv.br \\ ${ }^{5}$ Profa. adjunta do Depto. de \\ Nutrição e Saúde, UFV; Doutora \\ em Saúde da Mulher e da \\ Criança pela Fundação Oswaldo \\ Cruz. Endereço eletrônico: \\ raraujo@ufv.br
}

Recebido em: 11/03/2010 Aprovado em: 16/11/2010. 
A hipertensão arterial (HA) é um dos mais importantes fatores de risco cardiovascular e de doença renal, representando um grave problema de saúde pública no Brasil e no mundo (KEARNEY, 2005). No Brasil, a prevalência estimada de HA é de $35 \%$ na população acima de 40 anos sendo crescente na população mais jovem, representando cerca de 17 milhões de portadores (BRASIL, 2006).

As modificações no estilo de vida são consideradas fundamentais na prevenção e controle da HA. Alimentação adequada, redução e controle do peso corporal, prática de atividade física e o combate ao tabagismo e ao consumo excessivo de álcool representam os principais fatores ambientais modificáveis para redução do risco e incidência de doenças cardiovasculares (DCV) e HA (V DBHA, 2007). Destarte, há que se destacar que as modificações de hábitos de vida envolvem mudanças do padrão comportamental dos indivíduos e por isso não podem ser consideradas como escolhas individuais livres e descontextualizadas (COTTA et al., 2009).

A falta de adesão ao tratamento, inclusive às medidas não-farmacológicas, é provavelmente a causa da alta prevalência encontrada de hipertensos sem o controle da pressão, mesmo naqueles indivíduos em que a doença é conhecida (FUCHS; CASTRO; FUCHS, 2004). Somente 50\% dos indivíduos com doenças crônicas, como a HA, aderem às recomendações do tratamento, sendo que essa proporção tende a ser menor nos países em desenvolvimento. A não-adesão ao tratamento tem como consequências complicações médicas e psicossociais, redução da qualidade de vida e desperdício dos recursos assistenciais em saúde (WHO; ISH, 2003). Além de estar associada a variáveis como renda, escolaridade, sexo e idade, a adesão relaciona-se com as crenças e a percepção sobre a doença. Ressalta-se que o enfrentamento da HA envolve a compreensão de seu significado pelo hipertenso, de acordo com suas concepções sobre o processo saúde-doença-adoecimento (ARAÚJO; GARCIA, 2006).

No Brasil, o Programa de Saúde da Família (PSF), estratégia criada pelo governo em 1994 com o objetivo de reorganizar o Sistema Único de Saúde (SUS), visa à mudança de um modelo individualista e hospitalocêntrico, para um 
modelo com ênfase na Atenção Primária à Saúde (APS) e no trabalho em equipe

multi e interprofissional. Os princípios da integralidade, longitudinalidade, territorialidade e focalização na família - inscritos no PSF - fazem com que esta estratégia seja o modelo mais adequado para alterar o quadro das DCV (COTTA et al., 2008; COTTA et al., 2009). Não obstante, ainda que o PSF tenha aumentado o acesso dos portadores de HA aos serviços de saúde, observase uma baixa adesão ao tratamento, persistindo uma alta prevalência de fatores de risco na comunidade (RIBEIRO; COTTA; RIBEIRO, 2009).

O controle da HA constitui uma das áreas estratégicas da APS. Entretanto, as experiências educativas voltadas aos portadores de HA no país ainda são, em grande parte, restritas a prescrições normativas, sendo escassas as abordagens de educação em saúde sob a ótica da promoção da saúde, com uma perspectiva emancipatória dos sujeitos (TOLEDO; RODRIGUES; CHIESA, 2007). O tratamento e o controle da HA representam, nessa ótica, um desafio aos serviços e profissionais de saúde, que devem superar o distanciamento entre profissional e usuário e as práticas de saúde orientadas por tecnologias não flexíveis e desvinculadas da realidade dos indivíduos (COSTA et al., 2009).

Buscar compreender a relação dos portadores de HA com a enfermidade, com base em uma concepção subjetiva, que inclua seus sentimentos e percepções, amplia as possibilidades de medidas de prevenção e controle mais efetivas da doença (BARBOSA, 2000). Sendo assim, o objetivo deste trabalho ${ }^{1}$ foi conhecer e analisar as representações sociais de mulheres portadoras de HA, cadastradas em uma Unidade de Atenção Primária a Saúde (UAPS) e participantes de duas diferentes metodologias de educação em saúde, sobre a doença e seu convívio familiar. Exploraram-se os aspectos psicossociais relacionados aos sentimentos e comportamentos, capazes de influenciar o tratamento, a adesão e o controle da doença nos diferentes grupos, identificando-se os distintos significados que envolvem o convívio com essa enfermidade.

\section{Método}

\section{Descrição espaço-temporal e sujeitos estudados}

O estudo foi realizado em Porto Firme, município da Zona da Mata mineira, microrregião de Viçosa. O município possui uma população de 
10.404 habitantes, área territorial de $285 \mathrm{~km}^{2}$ e uma economia baseada principalmente na agricultura (IBGE, 2009). A pesquisa foi realizada na UAPS da área urbana de Porto Firme, que abriga duas equipes de Saúde da Família. Atualmente existem 1.361 famílias e um total de 626 portadores de HA cadastrados nesta UPAS.

Fizeram parte do estudo 26 mulheres, com idade entre 45 a 60 anos, diagnosticadas com HA, com ou sem diagnóstico de diabetes mellitus, cadastradas na UAPS urbana de Porto Firme. As participantes fizeram parte de um estudo de intervenção nutricional voltado às portadoras de hipertensão. Neste estudo, a amostra foi subdivida em dois grupos que diferiam quanto à abordagem/ metodologia em educação em saúde utilizada. No primeiro grupo a metodologia utilizada foi a orientação ao tratamento dietético da HA por meio de oficinas educativas mensais. No segundo grupo, os indivíduos além de participarem das oficinas educativas, receberam orientação individualizada e familiar por meio de visitas domiciliares periódicas.

A intervenção teve duração de cinco meses, de abril a agosto de 2009, e compreendeu cinco oficinas educativas e cinco visitas domiciliares, realizadas mensalmente. Adaptando-se às dinâmicas de atendimentos dos profissionais das equipes de Saúde da Família, as oficinas educativas foram realizadas simultaneamente às reuniōes mensais que já ocorriam na UAPS para o grupo de hipertensos e diabéticos. As oficinas de educação em saúde tinham duração média de uma hora e constavam de palestras dialogadas e dinâmicas interativas com a utilização de recursos diversos como cartazes, vídeos e demonstraçôes práticas. Nas visitas domiciliares, que tinham duração média de 45 minutos, eram realizadas orientações práticas de acordo com a realidade de cada família, por meio da observação sistemática da compra de gêneros alimentícios, preparo e consumo de alimentos.

\section{Coleta e análise dos dados}

O presente estudo fundamentou-se nos preceitos metodológicos da pesquisa qualitativa, por estar relacionado à compreensão dos significados que as pessoas atribuem a suas experiências e vivências e como elas compreendem o mundo em que vivem (POPE; MAYS, 2005). 
Para tanto, elegeram-se as representações sociais como princípio teóricometodológico. Segundo Moscovici (2003, p. 49), as "representações coletivas se constituem em um instrumento explanatório e se referem a uma classe geral de ideias e crenças, estão relacionados com uma maneira específica de compreender e comunicar - um modo que cria a realidade e o senso comum". Sendo assim, a representação social é uma forma dos indivíduos interpretarem sua realidade e a realidade social - é o pensamento do cotidiano, o que nos permite analisar esta realidade sob o olhar daquele que a vivencia (MARQUES; COTTA; ARAÚJO, 2009).

O corpus de análise dos dados qualitativos foi examinado por meio da análise de conteúdo, que compreendeu as seguintes etapas: 1) pré-análise; 2) exploração do material ;e 3) tratamento dos resultados, inferência e interpretação (BARDIN, 2004).

As informações foram obtidas através da realização de dois grupos focais - o primeiro constituído pelas usuárias que participaram das oficinas educativas, e o segundo, por aquelas que receberam orientação no domicílio, além da participação nas oficinas, realizadas em outubro de 2009, após as orientações nutricionais oferecidas nas oficinas e visitas domiciliares.

Para registro das informações, os relatos foram gravados em áudio e vídeo, após consentimento dos entrevistados, além de terem sido feitas anotações pertinentes para a compreensão da dinâmica do grupo, permitindo assim que as informações fossem transcritas de forma fidedigna, além de facilitar o retorno das pesquisadoras à fonte registrada, a checagem de informações e obtenção de novas conclusões.

Como forma de complementar e enriquecer o estudo, utilizaram-se também informaçôes sobre conhecimentos, percepções e práticas das participantes em relação à HA, obtidas por meio de entrevistas individuais, realizadas com o auxílio de questionário semiestruturado, aplicado às participantes do estudo antes da realização dos grupos focais. O questionário foi elaborado pela equipe responsável pelo trabalho de acordo com os objetivos da pesquisa e submetido a pré-teste.

\section{Aspectos éticos}

O trabalho foi aprovado pelo Comitê de Ética em Pesquisa da Universidade 
Federal de Viçosa (UFV), protocolo 030/2009 em consonância com o disposto na Resolução no 196/96 do Conselho Nacional de Saúde.

\section{Resultados e discussão}

\section{Caracterização dos sujeitos da pesquisa}

As mulheres participantes da pesquisa encontravam-se na faixa etária entre $45 \mathrm{e}$ 60 anos, sendo a média de idade do grupo de 53 anos. A maioria (85\%) possuía o ensino fundamental incompleto. Quanto ao estado civil, 96\% eram casadas ou possuíam relacionamento estável e $4 \%$ eram divorciadas. Apenas $11 \%$ possuíam trabalho formal com vínculo, enquanto $43 \%$ eram "do lar", $21 \%$ aposentadas ou pensionistas e $35 \%$ tinham trabalho informal ou eram trabalhadoras rurais. A renda familiar de cerca de $80 \%$ das mulheres se concentrava entre um e três salários mínimos, sendo que $53 \%$ delas contribuíam com a renda.

A média de idade das mulheres na ocasião do diagnóstico da HA foi de 42 anos, sendo que no momento da pesquisa a mediana de tempo de diagnóstico era de dez anos, sendo o mínimo de um e máximo de 35 anos. O diagnóstico se deu em $40 \%$ dos casos devido à ocorrência de uma crise hipertensiva; $21 \%$ em consulta médica devido aos sintomas da doença; $21 \%$ durante a gravidez; e $18 \%$ em consultas médicas por outros motivos.

\section{Atrativos semânticos e indicadores da saúde}

O conjunto de representações sociais tende a condensar-se, em alguns casos, em uma série de termos, de expressões, de imagens que exercem uma função de "atrativos semânticos", de modo que em torno de cada termo se situa um conjunto de expressões-chave, de palavras significativas das situações e concepções próprias de cada grupo, como é o caso de mulheres portadoras de HA de Porto Firme (DIAS et al., 2007). Os atrativos semânticos retirados das falas dessas mulheres nos levam a articular esse conjunto como um sistema de indicadores das citadas noções e representações sociais sobre HA, descritas no quadro 1.

Após análise e esquematização, é possível investigar as significações que são mais evidentes e representativas para esse grupo. 

relatos de mulheres portadoras de Hipertensão Arterial, município de Porto Firme, MG (2009)

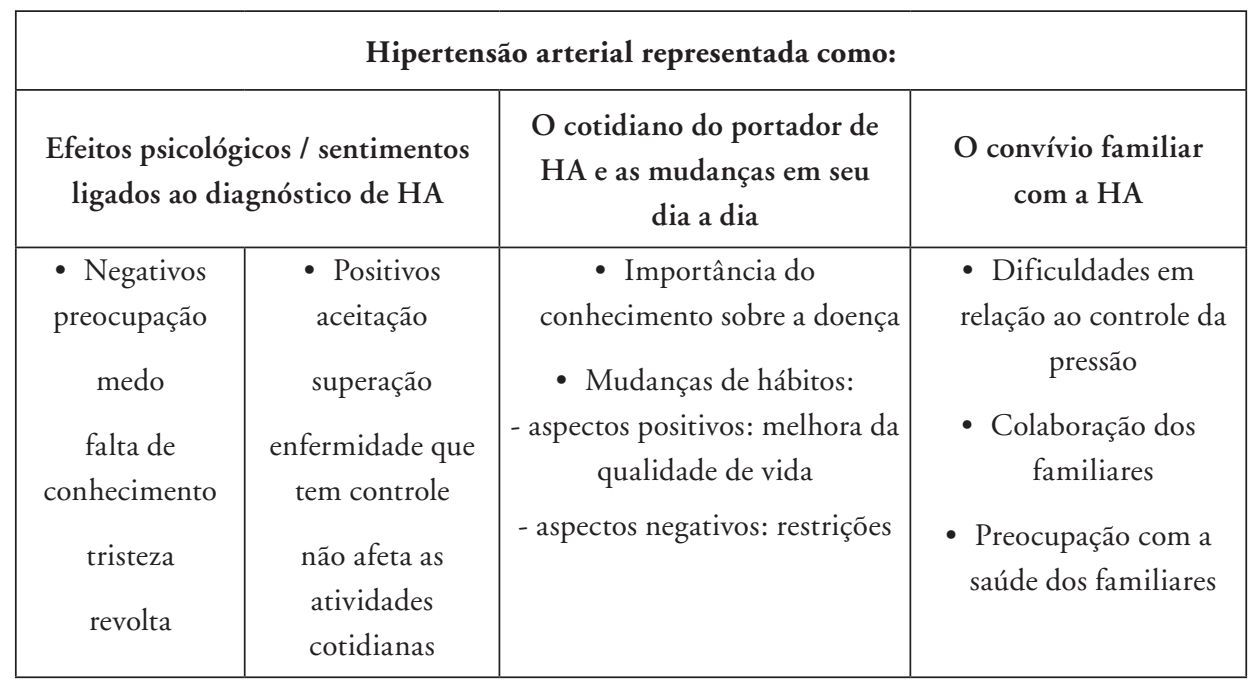

\section{Efeitos psicológicos/sentimentos ligados ao diagnóstico de HA Aspectos negativos}

Nesta categoria se destacam os sentimentos que denotam os efeitos psicológicos negativos do diagnóstico da HA, explicitados sobretudo pelas sensações de medo e preocupação, pelas possíveis consequências da doença e pela falta de conhecimento; e ainda pela tristeza e revolta, relacionadas à cronicidade da HA, condição que exige a adoção de novos hábitos, como por exemplo, o uso regular da medicação.

[...] Uma preocupação muito grande, visto que a hipertensão não tem cura [...]. Eu pra mim, eu senti muito preocupada. Preocupada porque a gente sabe que é uma coisa que a gente vai cuidar pro resto da vida e que é uma doença de alto risco se não houver cuidado. (1)

[...] Tristeza também porque sabe que tem que tomar o remédio pro resto da vida, além de correr muito risco de vida. (2)

A análise das falas evidencia o incômodo das mulheres com o diagnóstico da HA, pois impõe mudanças de hábitos e perda da qualidade de vida caso não seja controlada. 
No grupo estudado, cerca de $70 \%$ das mulheres possuíam outras doenças associadas à $\mathrm{HA}$, dentre elas: diabetes (25\%), dislipidemias (21\%), problemas relacionados a esôfago e estômago e problemas osteoarticulares (18\%). Aproximadamente $30 \%$ das mulheres do estudo eram portadoras de duas ou mais enfermidades concomitantemente à HA.

Eu falo com minhas amigas assim, aproveita mesmo até os cinquenta, passou dos cinquenta sobe a diabetes, a pressão alta, o colesterol [...]. (5)

Ah, eu pra falar bem verdade, eu num aceito de jeito nenhum [...] Que é pressão alta, é colesterol alto, diabetes [...] que eu fui criada aqui num tinha nada disso não, num tinha pressão, nem coração, tinha nada disso (4)

Os sentimentos aqui relatados pelas entrevistadas estão intimamente associados ao envelhecimento e ao delicado período que a mulher da meiaidade vivencia, com mudanças em seu corpo e ciclo vital que são encaradas muitas vezes como limitadores de uma vida ativa e saudável (MORI; COELHO, 2003).

Os desafios biopsicossociais vivenciados pelas mulheres de meia-idade se devem ao fato de que a maior expectativa de vida das mulheres nem sempre vem acompanhada de boas condições biopsicossociais. Fatores biológicos, estilo de vida, histórico de doenças, pobreza, baixa escolaridade e isolamento social afetam significativamente a saúde física e mental da população feminina (MORI; COELHO, 2003). Assim, um ponto importante a ser ressaltado se refere à medicalização a que nossa sociedade está habituada, bem como à formação dos profissionais de saúde, baseada no modelo biomédico e medicamentoso, onde se pensa poder resolver todos os problemas por meio de medicamentos (COTTA et al., 2009; CAMARGO JUNIOR, 2007). Hoje verifica-se um consumo abusivo de medicamentos psicotrópicos, constatandose, além do grave problema da automedicação, a prescrição médica excessiva de antidepressivos e ansiolíticos, sendo as mulheres de meia-idade as mais medicalizadas com psicotrópicos (RODRIGUES, 2003).

No presente estudo, cerca de $30 \%$ das mulheres usavam ansiolíticos e antidepressivos regularmente, sendo que em todos os casos o medicamento foi prescrito pelo médico. Carvalho et al. (1998) salientam que o fato de os tratamentos muitas vezes serem centrados no uso de medicamentos pode ser decorrente das próprias orientações recebidas dos profissionais de saúde. Isso pode ser demonstrado, em nosso estudo, pelas falas das mulheres entrevistadas. 
É remédio controlado, é negócio de depressão, é [...] outros remédios, rivotril, negó-

cio de calmante, aí é diariamente assim desse jeito [...] eu perguntei o médico se podia diminuir o remédio, mas ele falou assim que tem gente que toma até cinco dele; eu tomo três [...] mais o rivotril pra dormir, se eu não tomar eu não consigo dormir. (6)

Ô, mas você toma um tranquilizante, um antidepressivo [...] (7)

Dentro dos aspectos psicológicos negativos relativos ao diagnóstico da HÁ, destaca-se o uso regular da medicação anti-hipertensiva. As portadoras de HA demonstraram tristeza em relação ao uso de múltiplos medicamentos e descontentamento com a dificuldade do controle da PA, mesmo com uso da medicação.

[...] [a HA] ela ficou descontrolada, aí foi só trocando os remédios. (17)

Tem hora que eu ponho os remédio assim na mão e penso não vou tomar, mas tem que tomar né, fazer o que? (18)

Segundo a Organização Mundial de Saúde (OMS), menos da metade dos pacientes hipertensos consegue atingir a meta de PA com monoterapia. A maioria necessita da combinação de pelo menos dois fármacos e cerca de 30\% necessitam de três ou mais fármacos em combinação para atingir as metas de PA (OMS, 2003).

No grupo estudado, $82 \%$ das mulheres utilizavam dois ou mais medicamentos para o controle da PA. Cerca de 30\% utilizavam no mínimo cinco comprimidos de anti-hipertensivos diariamente. Esse achado vai ao encontro do estudo desenvolvido por Cotta et al. (2009) sobre o perfil sociossanitário e estilo de vida de hipertensos, onde se destaca a priorização do tratamento medicamentoso, em detrimento da adoção de estilos de vida saudáveis relacionados à dieta, prática de atividades físicas e redução do álcool, sal e fumo.

Muitas vezes, o uso prolongado do remédio remete os indivíduos a sua condição de "doentes", fazendo lembrar sua situação crônica de saúde, podendo gerar sentimentos de ansiedade, medo e tristeza (PERES; MAGNA; VIANA, 2003) - sentimentos estes vivenciados pelos usuários do presente estudo.

\section{Aspectos positivos}

Por outro lado, as mulheres também expressaram aspectos psicológicos positivos em relação à $\mathrm{HA}$, demonstrados pela aceitação, pela manutenção da rotina normal de atividades diárias e pela possibilidade de controle da doença.

Graças a Deus, até que eu controlo bem. [...] to com a vida normal, quase normal. E, tomando os remédios direitinho, né, tá tudo bem, graças a Deus. (7) 
Eu recebi a notícia com uma certa naturalidade, porque eu convivi a vida inteira com o meu pai que tinha pressão alta [...] Quando eu fiquei sabendo que tava com a pressão alta eu já sabia como controlar [...] Então, eu tomo os cuidados direitinho e vou vivendo a vida com tranquilidade. (10)

Os depoimentos demonstram posicionamentos distintos das mulheres em relação ao diagnóstico da HA. A convivência próxima com pessoas que possuíam a doença pareceu ser um dos fatores decisivos nessa diferença. As mulheres que possuíam familiares com essa condição apresentaram uma postura de maior aceitação ao diagnóstico. Esse fato pode estar relacionado ao diferente significado da HA construído por essas mulheres, ao maior acesso às informações de como controlar a doença, ou até mesmo ao fato de se conviver com outras pessoas portadoras de HA, o que parece apontar para uma postura mais favorável em relação à doença.

Na minha família [...] quem me conhece sabe que minha família é grande demais, só uma tia tem, porque justo eu puxar isso? Fiquei aborrecida com isso. (5)

A gente não quer que as pessoas sente isso, mas vai aumentando a turma, a gente vai falando assim, ai meu Deus, num é só eu, isso num ta só pra mim. São várias as minha colegas que tá. Num é que a gente quer que elas tem, mas com isso consola, né. (8)

A presença e convívio com parentes portadores de HA pareceram diminuir o estresse do diagnóstico nas participantes deste estudo. No entanto, deve-se atentar para o fato de que a supervalorização dos fatores de risco não-controláveis para HA, como a hereditariedade, pode afetar a percepção de autoeficácia do indivíduo no controle da doença (SOUSA, 2003).

Llor et al. (1995) apud Sousa (2003) discutem que as crenças etiológicas dos indivíduos podem explicar certas dificuldades no processo adaptativo à doença. Se os indivíduos atribuem as causas a seus próprios comportamentos inadequados, o sentimento de culpa pode interferir no processo adaptativo à doença. No entanto, se as causas forem atribuídas a fatores sobre os quais o indivíduo não pode atuar, como é o caso da hereditariedade, a aceitação do diagnóstico será mais resignada, porém com prejuízos ao controle da doença. Destaca-se, assim, a importância do suporte social para o indivíduo diagnosticado com a HA, de forma a desmistificar a doença e oferecer condiçôes para o seguimento adequado do tratamento após o diagnóstico.

No que se refere ao serviço de saúde, o trabalho em grupos com a equipe multiprofissional e a realização de atividades educativas são fatores preditores 
da adesão ao tratamento e importantes instrumentos de socialização, uma vez que nas atividades realizadas em grupos, os portadores de HA encontram espaço para verbalizar sintomas, ansiedades, frustraçôes e dificuldades junto a uma equipe que os apoia. Além disso, o grupo estimula a reflexão e amplia o nível de informação, pela troca de experiências (ARAÚJO; GARCIA, 2006), o que é explicitado pela fala de uma das participantes:

Como a gente trabalha em grupo assim [...] a gente sabe que mais alguém tem pressão alta, então, a gente vendo o grupo, uma vai ajudando a outra a superar as dificuldades, isso é importante. (10)

\section{O cotidiano do portador de hipertensão arterial e as mudanças impostas ao seu dia a dia}

A análise das falas das participantes das atividades em grupo indica que mais importante que o diagnóstico, o acesso ao apoio e à informação pela equipe de saúde é um fator propulsor na realização das mudanças de estilo de vida necessárias ao controle da doença.

[...] a partir do momento que você vai conhecendo, vai vendo a gravidade da doença, é que a gente vai tendo que mudar os hábitos, sim. (1)

A partir do momento que você vai tendo conhecimento muda bastante os hábitos de vida da gente sim. A gente convive e vai aprendendo também o que pode, o que não pode. (2)

Estudos presentes na literatura, investigando os conhecimentos, atitudes e práticas de indivíduos hipertensos, encontraram que nem sempre o conhecimento sobre os fatores de risco para DCV implica mudanças comportamentais (COTTA et al., 2009; AUBERT et al., 1998). Entretanto, a evidência científica aponta para uma maior adesão às medidas terapêuticas nos indivíduos de maior escolaridade. Além da associação à renda, também a escolaridade pode relacionar-se à adesão, já que o conhecimento sobre a doença e seu tratamento está diretamente relacionado à independência e à cooperação do indivíduo ao tratamento, sendo a adesão maior nos indivíduos com maior conhecimento sobre a doença (ARAÚJO; GARCIA, 2006; COTTA et al., 2008)

A importância do conhecimento sobre a doença fica clara ao se observar que o início do tratamento da HA nem sempre coincide com o momento do diagnóstico. Uma das participantes revelou que só iniciou o tratamento medicamentoso após agravamento da sintomatologia e perda da qualidade de vida, mostrando que a 
falta de conhecimento e percepção reais sobre as consequências da doença são fatores que podem prejudicar a adesão ao tratamento, mesmo após o diagnóstico.

$\mathrm{Na}$ hora, quando eu soube, foi numa situação de perda de familiar [...] fiquei dias no hospital internada, depois fui orientada pelo cardiologista que eu tinha que tomar medicação, mas relaxadamente eu não tomei. Passei um ano, dois anos, me queixando de dor de cabeça [...] até o ponto que eu cheguei aqui e o médico disse: você tem que tomar o remédio porque se você não tomar qualquer hora vai dar mais forte e vai ter um infarto. (11)

Considerando a baixa escolaridade do grupo estudado, em média quatro anos de estudo, enfatiza-se a importância do processo de educação em saúde para esclarecer e orientar as mulheres sobre os cuidados necessários para o controle da HA e melhora da qualidade de vida. No entanto, diante do discurso das mulheres, ressalta-se a necessidade de o processo de educação em saúde transpor medidas meramente prescritivas e normativas, restritas ao consultório médico, e/ou UAPS.

[...] você chega no consultório o médico fala só assim: você tem pressão alta, mas num dá um esclarecimento pra gente o que é a pressão alta, os riscos que a gente tem e nem o que a gente precisa fazer naquele momento. (1)

Estudo sobre o processo de educação em saúde para os hipertensos, realizado em PSFs de três cidades baianas, revelou que nas consultas médicas a tendência dominante era de medicalização, sendo a ação educativa secundária e superficial, sem apreensão de dimensões psicossociais e culturais do processo saúde-doença. A falta de adesão de alguns pacientes estudados foi discutida pelos autores como forma de resistência ou de exercício da autonomia frente à hegemonia médica (ALVES; NUNES, 2006). Nesse sentido, em nosso estudo, as experiências das oficinas de educação nutricional e das orientaçôes domiciliares, como formas mais dinâmicas e interativas de educação, foram muito positivas na adoção das mudanças alimentares recomendadas no tratamento da HA e no aumento do conhecimento sobre a doença.

Antes da nutricionista, as vezes eu ia no mercado comprar as coisas, num tava preocupando de olhar direitinho aquela tabela lá de alimentos [...] a partir do momento que ela apareceu aqui fazendo essas reuniōes, aqui que nós passamos a ter essa preocupação, até na hora de comprar o alimento, na hora de preparar, você vai preparar mais saudável. (10)

Estudo realizado com portadores de HA participantes de um grupo coordenado pela equipe de Saúde da Família de um município de pequeno porte no Rio Grande do Sul apontou a percepção positiva dos indivíduos em relação às atividades educativas em grupo e discutiu a efetividade desse tipo de 
atividade relacionada ao aumento da autoestima, autopercepção e autocuidado

dos indivíduos (SOUZA; POMATTI, 2003). Isso também foi observado pelas participantes das atividades de educação nutricional em Porto Firme:

Tem que ter consciência que a dieta é pra mim, o remédio é pra mim, num é para o médico, num é para a nutricionista. A nutricionista é ótima? É! [...] mas ela passou o conhecimento pra gente, cabe a nós agora o que? Assimilar o que ela passou e agir. [...] o que ela passou é lindo, maravilhoso, é ótimo. Agora, nós temos que ter consciência que nós vamos fazer igual ela ensinou, porque se não, não adianta. (1)

É a gente que tem que gostar da gente. Tem que ter consciência do que tem, do problema, gostar da gente, querer viver bem e ter uma vida saudável, com qualidade de vida também, que viver doente não é bom. (13)

Sobre as mudanças no cotidiano das portadoras de HA, as participantes mostraram sentimentos contraditórios. Por um lado, apontaram os aspectos positivos das mudanças no estilo de vida, referentes à melhora dos sintomas e da qualidade de vida, além de demonstrarem conseguir levar uma vida "normal" devido ao bom controle da doença.

Antes eu vivia aqui no posto, sempre aqui no posto, com dor de cabeça, com tontura, mas depois que eu controlei, aí acabou. Hoje eu me sinto bem, tomando os remédios e fazendo a alimentação adequada. (14)

É vida normal. [...] Ah, eu graças a Deus, num tenho problema nenhum. Levo minha vida normal. (12)

No entanto, ficou também explícita a visão das mudanças no cotidiano como restriçōes à vida "normal", alterando as atividades diárias e o convívio social.

Aí que vai mudar a alimentação, a questão de tá presa ao medicamento, você não pode esquecer o horário [...] você num é uma pessoa que pode fazer exercício físico exagerado, você num vai fazer uma lavação na sua casa tudo de uma vez num dia, porque você num vai dar conta. (1)

Ah, aí muda muita coisa, né, gente, já tem que controlar a alimentação, não pode ficar sem remédio de jeito nenhum, é o serviço [...] igual a gente que ta lá no sítio com um soleiro, a gente não pode ficar, logo a pressão vai e sobe, então você maneira um pouco. A alimentação muda demais. (12)

Estudo com portadores de HA hospitalizados na cidade de São Paulo-SP encontrou resultado semelhante. Os indivíduos consideravam as mudanças na vida após início do tratamento da HA como problemáticas, o que provocava sentimentos negativos relacionados à perda da capacidade física e as restrições, principalmente na alimentação (CASTRO; CAR, 2000). 
São vários os motivos apontados como causa para a resistência à adoção de hábitos de vida saudáveis, dentre eles o curso assintomático da doença, a subestimação de suas reais consequências e a dificuldade de mudança de padrōes comportamentais construídos ao longo do tempo (COTTA et al., 2008; AUBERT et al.; 1998). Nesse sentido, o trabalho de educação em saúde por uma equipe multiprofissional - que favoreça e facilite as mudanças necessárias e reforcem a importância do tratamento farmacológico e não farmacológico se mostra fundamental no controle adequado e melhora da qualidade de vida das portadoras de HA, como demonstrado pelas participantes do trabalho de educação nutricional realizado com o grupo estudado:

Antes eu num entendia, então era a falta de conhecimento do valor dos alimentos. A partir do momento que você, entende, tudo fica mais fácil. Hoje eu já num consigo mais comer o que eu comia antes. (1)

Igual ela explicou [...] tudo vale na explicação que a gente recebe do outro né, então do jeito que ela fala pra mim eu sigo direitinho a risca, né? (16)

\section{O convívio familiar com a hipertensão arterial}

A convivência das portadoras de HA no núcleo familiar revela diferentes faces do papel da família no enfrentamento da doença. As falas informam sobre a dificuldade em alcançar o controle da PA devido à ansiedade, preocupações e problemas relacionados à família.

É, problema de família também, faz a pressão subir. Problema, todo mundo tem, né, todo mundo tem problemas em casa [...] aí faz a pressão subir porque a gente fica nervosa, a gente fica preocupada. (3)

Estudo semelhante realizado com mulheres cadastradas em um programa de controle da HA em Teresina-PI revela o conflito das portadoras de HA na convivência com filhos e netos, no cuidado das pessoas da família e na sobrecarga de tarefas domésticas, que acarretam estresse psicoemocional e dificultam o controle da doença (COSTA e SILVA et al., 2008).

Em trabalho realizado por Peres et al. (2003), que investigou as crenças e percepçóes de portadores de HA sobre a doença, encontrou-se que grande parte dos indivíduos pesquisados referiu os aspectos emocionais, principalmente relacionados a problemas em casa, como fatores que dificultavam o controle da PA. 
Minayo (1988), em seu estudo sobre a concepção popular da etiologia das doenças, encontrou entre as causas referidas para as doenças na população estudada, o domínio psicossocial, relativo aos sentimentos e emoções prejudiciais à saúde, sobretudo relacionados às inter-relações familiares, da vizinhança e do ambiente de trabalho. De fato, cerca de $70 \%$ das mulheres do presente estudo relacionaram "nervosismo", traduzido por sentimentos como ansiedade, raiva e tristeza, aos fatores de risco e de controle da HA.

As V Diretrizes Brasileiras de Hipertensão Arterial fazem referência ao estresse psicoemocional e seu efeito na reatividade vascular e elevação transitória da PA. A abordagem dos aspectos psicoemocionais é sugerida como medida adicional ao tratamento não-medicamentoso, sendo útil na melhora da qualidade de vida, nível de estresse e na adesão ao tratamento, tanto pelo hipertenso quanto pelos familiares (V DBHA, 2007).

Quanto ao apoio e colaboração dos familiares ao tratamento da HA, foram revelados aspectos positivos e negativos em relação ao convívio familiar, principalmente em relação à alimentação. Os aspetos negativos se relacionavam à não-aceitação da família das mudanças alimentares, parte das medidas de controle da HA, como a redução do consumo de sal e gordura. Os familiares reclamavam da comida ou até mesmo preparavam as refeições separadamente. Esse comportamento ficou mais evidente no grupo que participou apenas das oficinas de educação em saúde nas UAPS, quando comparado ao grupo que recebeu as orientações domiciliares.

Acredita-se que essa diferença tenha ocorrido porque no grupo das mulheres que receberam as orientaçōes por meio de visitas domiciliares, ao contrário daquelas que só participaram das oficinas, o atendimento individualizado possibilitou a adequação das orientações às dificuldades de cada família, o que auxiliou na minimização dos conflitos gerados pelas mudanças dietéticas. Além disso, no grupo que recebeu as orientaçōes por meio das visitas domiciliares, houve maior contato entre o profissional e os familiares da portadora de HA, podendo estes esclarecerem dúvidas e acompanharem o trabalho, o que pode ter aumentado seu comprometimento com as mudanças dietéticas e auxílio no tratamento da familiar acometida pela HA. 
A minha filha fala que a minha comida é muito ruim, que a minha comida é muito sem gosto, que todo dia é a mesma coisa, que todo dia que ela chega é salada de repolho, salada de tomate, e que ela gosta mais de ir na casa dos outros. (3)

Meus filhos [...] eles já faz assim, a comida da senhora é essa; nós vão fazer pra nós, e faz pra eles. Eles faz separado, eles vai comer o deles gostoso e aí eu sei que eu num posso [...]. (5)

Estudo realizado com 400 familiares de hipertensos inscritos em uma Liga de Hipertensão Arterial em Fortaleza-CE mostrou que o saber dos familiares, apesar de elementar, era fundamental para viabilizar o tratamento da HA dos hipertensos, ressaltando a importância de capacitar a família para investir na adesão da pessoa hipertensa ao tratamento (SARAIVA et al., 2007).

Os aspectos positivos da convivência familiar se relacionaram à aceitação, pela família, das mudanças alimentares, e ainda ao apoio e ajuda dos familiares no tratamento.

[...] lá em casa num tem esse negócio não, tudo que eu faço meu marido come, num reclama nem nada, ele gosta também. (9)

Eu num faço separado não, e ele (marido) aceita do jeito que eu faço. E quando elas (filhas) pegam pra fazer também, elas fazem do mesmo jeito que eu faço. (17)

No grupo que recebeu as orientações domiciliares, além da aceitação, foi demonstrada também a adesão voluntária as medidas dietéticas e a preocupação com a própria saúde, principalmente por parte dos filhos.

Eu tenho uma menininha, minha menina fica me controlando, fica olhando eu colocar minha comida no prato pra ver se eu coloquei certo [...] ela ta com oito anos e ela fala: "num quero ser gorda, não" (11)

Inclusive até meu filho também, ele tem 16 anos, ele ta um pouco gordo, aí ele falou "ô mãe, eu vou acompanhar a senhora no regime. (16)

O suporte familiar é especialmente importante na adesão do portador de HA ao tratamento, uma vez que a HA exige mudanças de estilo de vida que afetam também os outros elementos do núcleo familiar, sendo a participação da família altamente relevante na aquisição e manutenção de hábitos saudáveis (ARAÚJO; GARCIA, 2006), o que é evidenciado pela fala de uma das participantes:

É uma das mudanças mais difíceis porque a alimentação acaba sendo uma coisa que envolve outras pessoas também da família, acho que por isso também. (10) 
Em relação ao convívio familiar, também se evidenciou a preocupação das mulheres com a saúde e a adoção de hábitos saudáveis pela família.

Se nós temos essa consciência, a gente como mãe, nós vamos ter que começar, mostrar pro filho da gente olha [...] a alimentação tem que ser assim, e educar mesmo, ser rígido, não adianta só falar. (1)

A gente tem que pensar muito, pensar muito na nossa família, e quando a gente vai fazer uma dieta tem que ter consciência também que a dieta não é só para mim, é algo para todos da nossa família. (2)

No domicílio, a mulher exerce papel central no cuidado dos familiares em relação à higiene, alimentação, tratamento de enfermos e autocuidado (DIAS et al., 2007). São por isso, protagonistas na manutenção e transformação dos hábitos alimentares das famílias.

Na temática das políticas públicas saudáveis, a mulher se destaca como principal agente promotor da saúde em todo o mundo, ressaltando-se a consequente necessidade desse grupo em ter acesso à informação e redes de apoio (BRASIL, 2002). Assim, a proposta de trabalhar com mulheres portadoras de HA em seu domicílio apresentou-se como estratégica, uma vez que as mulheres exercem papel central na alimentação da família, ao mesmo tempo que são influenciadas diretamente pela relação que estabelecem com os outros integrantes do núcleo familiar no convívio com a doença, o que afeta suas atitudes frente ao tratamento, incluindo a alimentação.

Nesse contexto, a família é compreendida como importante rede de apoio que pode tanto facilitar quanto dificultar o seguimento do tratamento da HA, sendo por isso alvo essencial das ações de educação em saúde, que não devem ser restritas apenas ao portador de HA. Como foi o caso das orientaçôes domiciliares, que demonstraram facilitar as mudanças no núcleo familiar, diminuir conflitos em relação à alimentação e contribuir para a adesão.

\section{As representações sociais e as dimensões da adesão ao tratamento anti-hipertensivo}

A adesão é um processo comportamental complexo, que ao contrário da opinião comum, de que os pacientes são os únicos responsáveis pelo seguimento do tratamento, é influenciado por diversas variáveis como o meio ambiente, os 
profissionais e os serviços de saúde (GUSMÃO; MION, 2006). A OMS caracteriza a adesão como um processo multidimensional influenciado por cinco dimensões principais: fatores relacionados ao indivíduo (1), fatores relacionados às características da doença (2), fatores relacionados à terapia (3), fatores econômicos e sociais (4), sistemas de saúde e fatores relacionados ao relacionamento com os profissionais de saúde (5) (WHO, ISH, 2003).

Buscou-se, através das representações das mulheres deste estudo sobre a HA, identificar fatores relacionados às diferentes dimensões da adesão, de forma a contribuir para a compreensão das possíveis variáveis envolvidas no processo de tratamento da doença nesse grupo (figura 1).

Quanto aos fatores relacionados ao indivíduo, as diferentes percepções das mulheres em relação à doença e o conhecimento sobre a HA foram encontrados como possíveis fatores interferentes na adesão. Destaca-se que um maior conhecimento sobre essa condição se mostrou como fator preditor da adesão nesse grupo.

Figura 1. Dimensões da adesão de mulheres portadoras de hipertensão arterial do município de Porto Firme, MG (2009)

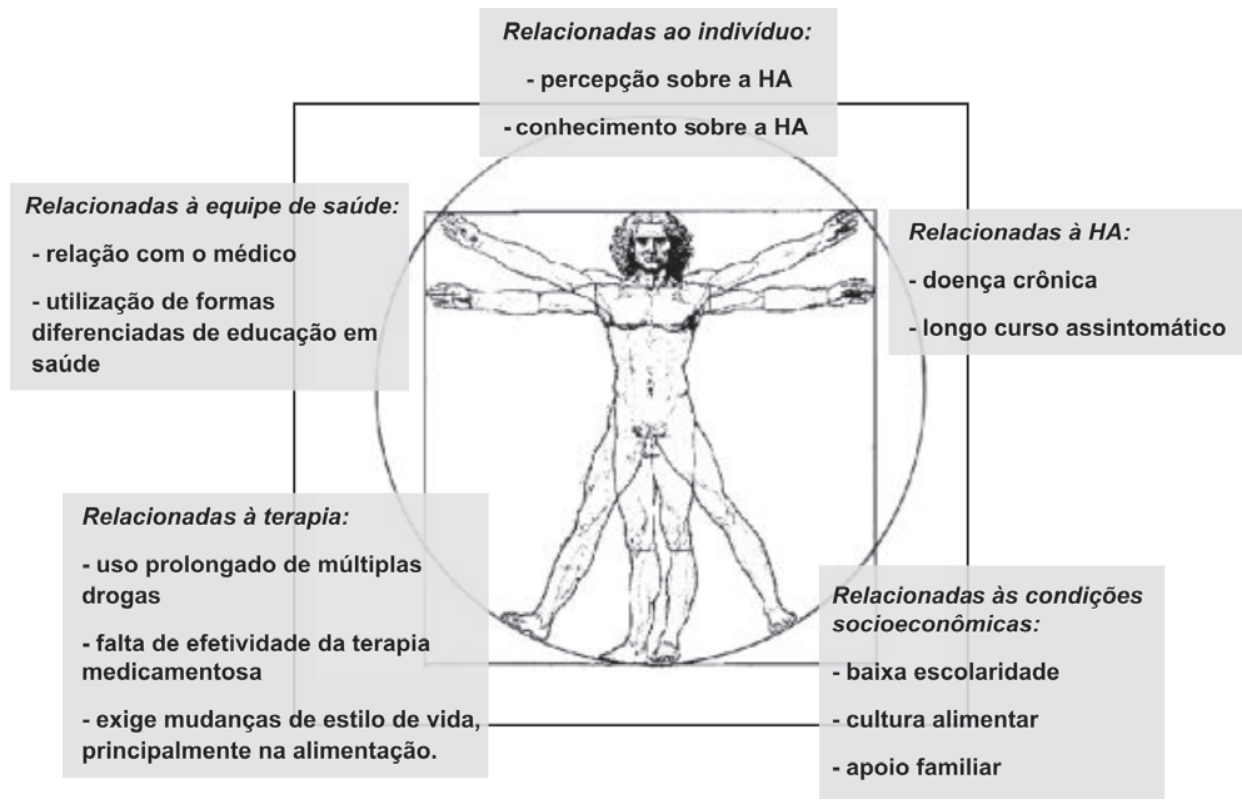


Os fatores relacionados à terapia são fundamentais na compreensão do processo

de adesão no caso da HA. No grupo estudado o tratamento farmacológico apresentou dificuldades em relação ao uso prolongado de múltiplas drogas e a baixa efetividade do tratamento medicamentoso em alguns casos, acarretando trocas contínuas de medicamento. Da mesma forma, o tratamento nãofarmacológico também se mostrou como um desafio, porque envolve mudanças de estilo de vida, relacionadas principalmente à alimentação, retratadas pelas participantes como a principal dificuldade encontrada no tratamento da HA.

Em relação às características da doença, por se tratar de uma enfermidade crônica, com evolução clínica lenta, porém permanente e progressiva, a HA gerou sentimentos de medo e preocupação que, no entanto, nem sempre se traduziram de forma imediata nas mudanças de estilo de vida, provavelmente devido ao longo curso assintomático da doença e à supervalorização da terapia medicamentosa como forma de tratamento.

Os fatores econômicos não foram explorados de forma direta nessa investigação. No entanto, acredita-se que a baixa renda observada no grupo se relacione também com a baixa escolaridade que, associada ao baixo nível de conhecimento sobre a doença, pode constituir um fator limitante a adesão.

Quanto aos fatores sociais, a cultura alimentar da região pode afetar a adesão às mudanças dietéticas, pela associação da dieta a restrições da vida social, como a participação em festas e confraternizações que ofereçam alimentos não recomendados para os portadores de HA. Além disso, o suporte social, representado sobretudo pela família, mostrou-se como fator essencial na adesão das mulheres, sobretudo às mudanças dietéticas.

Por último, os fatores relacionados às equipes/sistemas de saúde foram evidenciados nas falas das participantes, principalmente sobre a relação com o médico e em relação ao processo de educação em saúde. Sobre a relação médico/ usuário, a hegemonia médica e o caráter normativo das consultas emergiram como fatores limitantes da adesão, sobretudo as medidas não-farmacológicas. Por outro lado, a utilização de estratégias diferenciadas por uma equipe multidisciplinar, como as oficinas de educação em saúde e as orientações domiciliares, foi apontada como favorável à adesão. 


\section{Espaços de adesão ao tratamento anti-hipertensivo}

Dimensionar os fatores relacionados à adesão identificados, desde o âmbito coletivo ao individual, relacionando esses aspectos aos espaços institucional e social, conforme as representações e atitudes das mulheres frente à doença, e as observações in loco dos pesquisadores, também foram objeto deste estudo (figura 2).

\section{Figura 2. Subespaços construídos a partir das representaçóes sociais} de portadoras de HA sobre a doença e fatores relacionados à adesão ao tratamento, município de Porto Firme, MG (2009).

II

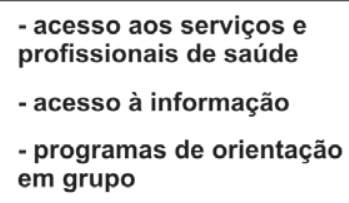

\section{Institucional}
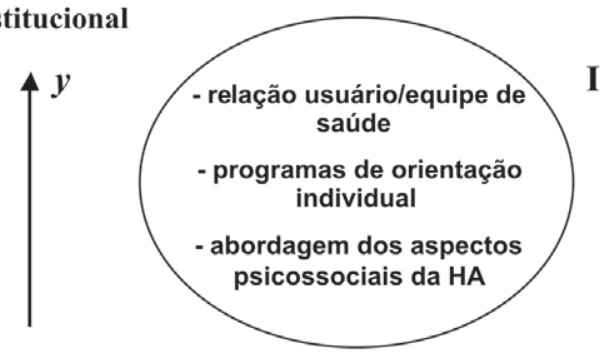

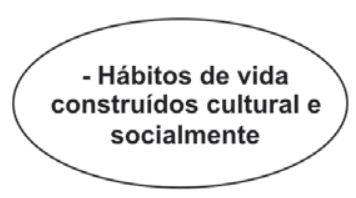

III

Coletivo

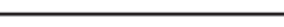

Fatores relacionados à adesão

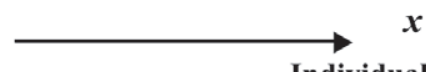

Individual

\section{IV}

\section{Social}

Adaptado e modificado de Dias et al, 2007

No eixo $y$, a parte superior demonstra o espaço institucional, representado principalmente pelos serviços de saúde. A parte inferior representa o espaço social. No eixo $\boldsymbol{x}$, apresenta-se a percepção das mulheres sobre os fatores relacionados à adesão ao tratamento no âmbito coletivo e individual dimensionados nos quadrantes da figura, dentro dos espaços institucional e social.

No quadrante I, encontram-se as representações que relacionam a adesão à relação direta das mulheres com o serviço/equipe de saúde. A relação entre 
usuário e equipe de saúde é sabidamente um fator determinante na adesão do indivíduo portador de HA ao tratamento (ARAÚJO; GARCIA, 2006). Nesse sentido, considerando a importância demonstrada pelas mulheres deste estudo aos aspectos psicossociais no controle da doença, pode-se inferir que a construção de parcerias entre profissional e paciente e o fornecimento de suporte emocional propicia melhores resultados quando comparado a condutas simplesmente normativas (WHO; ISH, 2003). Também as dificuldades relacionadas à terapia medicamentosa e não-medicamentosa parecem ser mais bem superadas, considerando-se as dificuldades e preferências individuais e familiares, sendo que programas de orientação individual e familiar, como as orientações domiciliares realizadas com as mulheres deste estudo, apontaram melhor adesão ao tratamento.

No quadrante II, é apresentada a relação entre a instituição e o coletivo nos fatores interferentes na adesão. $\mathrm{O}$ acesso aos serviços e profissionais de saúde apresenta extrema importância, uma vez que todas as mulheres estudadas eram cadastradas ao serviço e por isso tinham acesso a consultas médicas, de enfermagem e a medicamentos gratuitamente, sendo que $82 \%$ das mulheres afirmaram frequentar os médicos da UAPS. No entanto, constatou-se, por meio do relato das mulheres, a dificuldade na marcação de consultas, uma vez que as consultas eram pré-agendadas por meio da distribuição de senhas, o que gerava filas e desestimulava consultas mais frequentes. Esse fato pode explicar parcialmente a alta frequência (cerca de 60\%) de mulheres que se consultavam esporadicamente, somente quando se sentiam mal.

$\mathrm{O}$ acesso à informação foi revelado pelas participantes do estudo como importante fator preditor de adesão, sendo os programas de orientação em grupo uma estratégia efetiva para aumentar o conhecimento das portadoras de HA sobre a doença e o tratamento. As reuniōes mensais que ocorriam na UAPS para os portadores de HA foram apontadas como forma importante de conscientização, sobretudo em relação ao uso da medicação anti-hipertensiva. No entanto, estratégias mais específicas, com conteúdos definidos e metodologias diversificadas (construções coletivas vivenciadas pelo usuário, cartazes, vídeos, demonstrações práticas), como as oficinas de educação em saúde, pareceram mais efetivas na consolidação do conhecimento pelas mulheres do estudo.

No quadrante III encontram-se as representações das mulheres sobre os fatores intervenientes na adesão no espaço social, pensando nas relações com a 
coletividade. Foi possível observar e mensurar, durante o estudo de intervenção nutricional em Porto Firme, o alto consumo de sal, açúcar e gordura, fato observado também em outros municípios da região (COTTA et al., 2009; BATISTA et al., 2006). Esse hábito, construído social e culturalmente, interfere na adesão tanto em relação à dificuldade em mudar hábitos construídos ao longo da vida, quanto em relação às restrições à vida social.

Ainda no espaço social, no quadrante IV tem-se a representação das mulheres sobre os fatores sociais ligados à adesão em um contexto mais específico, representado pela família, amigos e colegas. O suporte familiar aparece como importante fator interveniente na adesão das participantes do estudo. Além disso, pôde-se observar durante o estudo a interação entre as participantes, que se ajudavam, trocavam experiências e discutiam sua adaptação às mudanças dietéticas. $\mathrm{O}$ suporte social construído pelas relações próximas às mulheres pareceu favorecer, além da adoção das mudanças, sua manutenção em longo prazo.

\section{Considerações finais}

As representações sociais das mulheres portadoras de HA neste estudo evidenciaram sentimentos e posicionamentos distintos em relação à doença, sua convivência e as relações estabelecidas entre a doença e seu meio social; fatores que afetam a adesão ao tratamento.

Os sentimentos de ansiedade, medo e revolta relacionados ao diagnóstico e as dificuldades referentes ao tratamento relacionaram-se a diferentes dimensões e espaços da vida dessas mulheres, sendo que um adequado acesso à informação associado ao suporte social pareceu ser um fator favorável à adesão ao tratamento.

Evidencia-se que as práticas educativas, além de fornecerem informações necessárias à terapia anti-hipertensiva, devem estimular a autopercepção da doença e corresponsabilização do indivíduo com seu próprio cuidado, estimulando assim a autonomia. Nesse sentido, pode-se inferir que as oficinas educativas em grupo e as orientações domiciliares mostraram-se importantes estratégias de educação em saúde, efetivas para aumentar adesão às orientações dietéticas voltadas às portadoras de HA.

Agregar os familiares as atividades de educação em saúde também se mostrou importante para facilitar as mudanças de estilo de vida no núcleo 
familiar e aumentar a adesão do hipertenso ao tratamento. $\mathrm{O}$ conhecimento das representações sociais do portador de HA permitiu considerar suas próprias necessidades em relação ao tratamento e não apenas as indicações dos profissionais.

Destarte, destaca-se a necessidade do trabalho multiprofissional e interdisciplinar para lidar com essa complexa demanda que envolve o portador de HA e seu tratamento, espaço este que deve ser mais bem explorado no âmbito da APS.

\section{Referências}

ALVES, V.S.; NUNES, M.O. Educação em saúde na atenção médica ao paciente com hipertensão arterial no Programa Saúde da Família. Interface - Comunic, Saúde, Educ, Botucatu, v.10, n.19, p. 131-147, 2006.

ARAÚJO, G.B.S.; GARCIA, T.R. Adesão ao tratamento anti-hipertensivo: uma análise conceitual. Rev Eletrônica Enferm, Goiânia, v.8, n.2, p. 259-272, 2006.

AUBERT, L. et al. Knowledge, Attitudes, and Practices on Hypertension in a Country in Epidemiological Transition. Hypertension, Dallas, v.31, p. 1136-45, 1998.

BARBOSA, M.R.J. Vivenciando a hipertensão arterial: construção de significados e suas implicaçôes para a vida cotidiana. Rev Bras Enferm, Brasília, v.3, n.4, p.574-83, 2000.

BARDIN, L. Análise de conteúdo. Lisboa: Edições 70, 2004. 223 p.

BATISTA, M.C.R. et al. Avaliação dietética dos pacientes detectados com hiperglicemia na "Campanha de Detecção de Casos Suspeitos de Diabetes" no município de Viçosa, MG. Arq Bras Endocrinol Metabol, São Paulo, v.50, n.6. p.1041-49, 2006.

BRASIL. Ministério da Saúde. Secretaria de Políticas de Saúde. Projeto Promoção da Saúde: as Cartas da Promoção da Saúde. Brasília: Ministério da Saúde, 2002. 56 p. (Textos Básicos em Saúde).

CAMARGO JUNIOR, K.R. As Armadilhas da concepção positiva de saúde. Physis, Rio de Janeiro, v.17, n.1. p.63-76, 2007.

CARVALHO, F.; TELAROLLI JUNIOR, R.; MACHADO, J.C.S. Uma investigação antropológica na terceira idade: concepções sobre a hipertensão arterial. Cad Saúde Pública, Rio de Janeiro, v.14, n.3, p.617-21, 1998.

CASTRO, V.D.; CAR, M.R. O cotidiano da vida de hipertensos: mudanças, restriçōes e reações. Rev Esc Enf USP, São Paulo, v.34, n.2, p.145-53, 2000.

COSTA E SILVA, M.E.D.C.; et al. Representaçōes sociais de mulheres portadoras de hipertensão arterial. Rev Bras Enferm, Brasília, v.61, n.4, p.500-7, 2008.

COSTA, G.D.; et al. Saúde da família: desafios no processo de reorientação do modelo assistencial. Rev Bras Enferm, Brasília, v.62, n.1, p.113-18 2009. 
COTTA, R.M.M.; et al. Perfil sociossanitário e estilo de vida de hipertensos e/ou diabéticos, usuários do Programa de Saúde da Família no município de Teixeiras, MG. Ciênc Saúde Coletiva, Rio de Janeiro, v.14, n.4, p.1251-60, 2009.

COTTA, R.M.M. et al. Reflexões sobre o conhecimento dos usuários no contexto do Programa de Saúde da Família: a lacuna entre o saber técnico e o popular. Physis, Rio de Janeiro, v.18, n.4, p.745-66, 2008.

DIAS, G. et al. A vida nos olhos, o coração nas mãos: concepçôes e representações femininas do processo saúde-doença. Hist Cienc Saude-Manguinhos, Rio de Janeiro, v.14, n.3, p.779800, 2007.

FUCHS, S.C.; CASTRO, M.S.; FUCHS, F.C. Adesão ao tratamento anti-hipertensivo: análise das evidências. Rev Bras Hipertens., São Paulo, v.7, n.3, p. 90-93, 2004.

GUSMÃO, J.L.; MION, J.R. Adesão ao tratamento: conceitos. Rev Bras Hipertens, Ribeirão Preto, v.13, n.1, p.23-5, 2006.

INSTITUTO BRASILEIRO DE GEOGRAFIA [homepage na internet]. Cidades. Minas Gerais. Porto Firme. Disponível em: http://www.ibge.gov.br/cidadesat/topwindow.htm?1. Acesso em 30 ago 2009.

KEARNEY, P.M. Global burden of hypertension: analysis of worldwide data. Lancet, London, v.365, p.217-23, 2005.

MARQUES, E.S.; COTTA R.M.M.; ARAÚJO, R.M.A. Representações sociais de mulheres que amamentam sobre a amamentação e o uso de chupeta. Rev Bras Enferm, Brasília, v.62, n.4, p.562-69, 2009.

MINAYO, M.C.S. Saúde-doença: uma concepção popular da etiologia. Cad Saúde Publica, Rio de Janeiro, v.4, p.363-81, 1988.

BRASIL. Ministério da Saúde. Hipertensão arterial sistêmica. Brasília: MS, 2006. (Normas e Manuais Técnicos).

MORI, M.E.; COELHO, V.L.D. A vida ouvida: a escuta psicológica e a saúde da mulher de meia idade. Est Pesq Psic, Rio de Janeiro, v.3, n.2, p.1-12, 2003.

MOSCOVICI S. As representaçôes sociais: investigações em psicologia social. Petrópolis: Vozes, 2003. $404 \mathrm{p}$.

ORGANIZAÇÃO MUNDIAL DA SAÚDE. Adherence to long term to long therapies: evidence for action. Geneva: WHO, 2003. 196 p.

ORGANIZAÇÃO PAN-AMERICANA DE SAÚDE. Doenças crônico-degenerativas e obesidade: estratégia mundial sobre alimentação saudável, atividade física e saúde. Brasília: OPAS, 2003. $60 \mathrm{p}$. 
PERES, D.S.; MAGNA, J.M.; VIANA, L.A. Portador de hipertensão arterial: atitudes, crenças, percepções, pensamentos e práticas. Rev. Saúde Pública; São Paulo, v.37, n.5, p.63542, 2003.

POPE, C.; MAYS, N. Pesquisa qualitativa na atenção à saúde. Porto Alegre: Artmed, 2005. RIBEIRO, A.G.; COTTA, R.M.M.; RIBEIRO, S.M.R. A Promoção da Saúde e a Prevenção Integrada dos Fatores de Risco para Doenças Cardiovasculares. Ciênc Saúde Coletiva [online]. 2009 [cerca de 15 p]. Disponível em: http://www.abrasco.org.br/cienciaesaudecoletiva/artigos/artigo_int.php?id_artigo=4478. Acesso em: 20 nov 2009.

RODRIGUES, J.T. A medicação como única resposta: uma miragem do contemporâneo. Psicol Estud, Maringá, v.8, n.1, p.13-22, 2003.

SARAIVA, K.R.O. et al. Saber do familiar na adesão da pessoa hipertensa ao tratamento: análise com base na educação popular em saúde. Texto Contexto Enferm, Florianópolis, v.16, n.2, p.263-70, 2007.

SOUSA, M.R.M.G.C. Estudo dos conhecimentos e representações de doença associados à adesão terapêutica nos diabéticos tipo 2. Braga, 2003. Dissertação (Mestrado em Educação para a Saúde) - Universidade do Minho, 2003.

SOUZA, R.C.; POMATTI, D.M. Repercussão das atividades educativas no dia-a-dia dos hipertensos participantes de um grupo. Boletim da Saúde Porto Alegre, Porto Alegre, v.17, n.2, p.147-58, 2003.

TOLEDO, M.M.; RODRIGUES, S.C.; CHIESA, A.M. Educação em saúde no enfrentamento da hipertensão arterial: uma nova ótica para um velho problema. Texto Contexto Enferm, Florianópolis, v.16, n.2, p.233-238, 2007.

V DIRETRIZES BRASILEIRAS DE HIPERTENSÃO ARTERIAL. Arq Bras Cardiol, Rio de Janeiro, v.89, n.3, p.24-79, 2007.

WORLD HEALTH ORGANIZATION; INTERNATIONAL SOCIETY OF HYPERTENSION WRITING GROUP. 2003 World Health Organization (WHO) / International Society of Hypertension (ISH) statement on management of hypertension. J Hypertens, v.21, p.1983-92, 2003.

\section{Nota}

${ }^{1}$ Este trabalho foi financiado pela FAPEMIG, processo no APQ-00197-09. 
Social representation of women with hypertension in relation to the disease: unraveling the adherence to the treatment in relation to the schedule of the Family Health The lack of compliance with treatment and the consequent lack of control of hypertension represent a major challenge to primary care in Brazil. Understanding the subjective relationship of patients with hypertension can expand the possibilities of more effective control measures. The aim was to understand and analyze the social representations of women with hypertension about the disease and their family environment. Study participants were 26 women diagnosed with hypertension and registered in a Unit of Primary Health Care in the city of Porto Firme, Brazil. The study was based on qualitative research and elected social representations as theoretical and methodological principle. The data, collected through focus groups, interviews and notes in a diary, were examined through content analysis. In the analysis emerged semantic attractions depicting the representations of women on hypertension - psychological effects and feelings related to the diagnosis of hypertension; daily life of patients with hypertension and changes in their daily lives; and family life with hypertension - through which have identified different dimensions and spaces connected to membership, both individually and collectively, emphasizing access to information associated with social support as a factor in favor of compliance with the treatment.

> Key words: qualitative research, health education, hypertension. 